OPEN ACCESS

Edited by:

Ludmila Brunerova,

Charles University, Czechia

Reviewed by:

Jan Rosa,

Affidea Praha s.r.o., Czechia

Jonathan H. Tobias,

University of Bristol, United Kingdom

*Correspondence:

Enisa Shevroja

enisa.shevroja@chuv.ch

Didier Hans

didier.hans@ascendys.ch

Specialty section:

This article was submitted to

Bone Research,

a section of the journal

Frontiers in Endocrinology

Received: 26 March 2018 Accepted: 03 September 2018 Published: 24 September 2018

Citation:

Shevroja E, Lamy O and Hans D

(2018) Review on the Utility of

Trabecular Bone Score, a Surrogate of

Bone Micro-architecture, in the

Chronic Kidney Disease Spectrum and in Kidney Transplant Recipients.

Front. Endocrinol. 9:561.

doi: 10.3389/fendo.2018.00561

\section{Review on the Utility of Trabecular Bone Score, a Surrogate of Bone Micro-architecture, in the Chronic Kidney Disease Spectrum and in Kidney Transplant Recipients}

\author{
Enisa Shevroja*, Olivier Lamy and Didier Hans* \\ Bone \& Joint Department, Center of Bone Diseases, Lausanne University Hospital, Lausanne, Switzerland
}

Chronic kidney disease (CKD) is defined as abnormalities of kidney structure or function, present for $>3$ months, with implications for, among others, bone health. Advanced stages of CKD have an increased risk of fragility fractures. Trabecular bone score (TBS) is a relatively new gray-level textural parameter, which provides information on bone microarchitecture and has been shown to be a good predictor of fragility fractures independently of bone density and clinical risk factors. We aimed to review the scientific literature on TBS and its utility along the CKD spectrum and in kidney transplant recipients. In total, eight articles had investigated this topic: one article in patients with reduced kidney function, two in patients on hemodialysis, and five in kidney transplant recipients. In general, all the studies had shown an association between lower values of TBS and reduced kidney function; or lower TBS values among the hemodialysis or kidney transplant patients compared to healthy controls. Moreover, TBS was shown to be a good and independent predictor of fragility fractures in patients with CKD or who underwent kidney transplantation. TBS postulates itself as a valuable marker to be used in clinical practice as an assessor of bone microarchitecture and fracture risk predictor in these specific populations. However, evidence is to some extent limited and larger follow-up case-control studies would help to further investigate the TBS utility in the management of bone health damage and increased fracture risk in patients with CKD or kidney transplant.

Keywords: trabecular bone score, chronic kidney diseases, fracture prediction, bone microarchitecture, bone and bones

\section{INTRODUCTION}

The Kidney Disease Improving Global Outcome (KDIGO) defines chronic kidney disease (CKD) as abnormalities of kidney structure or function, present for $>3$ months, with implications for health (1). CKD is classified based on the cause (i.e., diabetes or hypertension); glomerular filtration rate (GFR) (stage 1: GFR $\geq 90 \mathrm{ml} / \mathrm{min} / 1.73 \mathrm{~m}^{2}$, stage 2: GFR $=60-89 \mathrm{ml} / \mathrm{min} / 1.73$ $\mathrm{m}^{2}$, stage 3a: GFR $=45-59 \mathrm{ml} / \mathrm{min} / 1.73 \mathrm{~m}^{2}$, stage $3 \mathrm{~b}: \mathrm{GFR}=30-44 \mathrm{ml} / \mathrm{min} / 1.73 \mathrm{~m}^{2}$, stage 4 : GFR $=15-29 \mathrm{ml} / \mathrm{min} / 1.73 \mathrm{~m}^{2}$ and stage $5:$ GFR $<15 \mathrm{ml} / \mathrm{min} / 1.73 \mathrm{~m}^{2}$ ); and albuminuria (normal 
to mildly increased: $<30 \mathrm{mg} / \mathrm{g}$, moderately increased: $30-300$ $\mathrm{mg} / \mathrm{g}$ and severely increased: $>300 \mathrm{mg} / \mathrm{g}$ ). The presence of a higher albuminuria in each stage of GFR carries a poorer prognosis for the progression of CKD (1).

Among other health consequences, the declines in kidney function cause changes in bone mineral metabolism which weaken the skeletal system $(2,3)$. The CKD abnormalities that are believed to independently or collectively alter bone metabolism (remodeling or mineralization) are: secondary hyperparathyroidism, abnormalities in 1,25-dihydroxyvitamin D synthesis, phosphorus retention, chronic metabolic acidosis, and elevated sclerostin and/or fibroblast growth factor 23 levels (4-8). These abnormalities occur early in the course of CKD to become almost universal in patients with advanced CKD (9, 10). All together constitute a systemic mineral metabolism derangement known as CKD-mineral and bone disorder (CKD-MBD), a term suggested by KDIGO (3). It is well-recognized that advanced stages of CKD (stages 3a-5) place individuals at particularly high risk of fragility fractures, due to the alterations of bone strength (11-13). This increase in fracture risk is attributable to the combination of CKD-induced changes in bone and mineral metabolism, and the classic fracture risk factors observed also in the non-CKD population, such as: age, sex, previous fracture, diabetes mellitus or glucocorticoid use (14). Fragility fractures will eventually enhance the economic and social burden of CKDMBD (14).

Therefore, the evaluation of the risk of fracture in these specific stages is very important. It is a silent agreement among the bone health community that in the earlier stages of CKD (stage 1-3), the fracture risk assessment is made as in the general population; whereas by the time a patient progresses the advanced stages (stages 4-5), bone metabolism derangements become so dominant and the fracture risk increases so much that the general population's criteria may not be relevant anymore $(15,16)$. Bone histomorphometry remains the gold standard to evaluate bone abnormalities in the advanced CKD-MBD (3). Nevertheless, as a costly and invasive technique, its routine clinical use is very limited. Recent studies introduced enough evidence that bone mineral density (BMD) as measured from the dual-energy X-ray absorptiometry (DXA) scans, is a good predictor of fractures in the spectrum of CKD stages $3 a$ to stage 5 on dialysis (17-20), which allowed KDIGO for recommending BMD measurement in their 2017 update (1). However, as in the non-CKD patients, the relevance of BMD is limited due to its overestimation in the presence of scoliosis, osteoarthritis at the lumbar spine, vascular and/or joint calcifications. Moreover, it has been suggested that both bone mass and texture need to be assessed to provide an accurate assessment of fracture risk in individuals with or without CKD (14). As BMD only measures one factor, bone mass, providing no information on bone texture, which is also adversely affected in CKD, it cannot be a stand-alone risk factor for making management decisions (14).

Trabecular bone score (TBS) is a relatively new graylevel textural parameter, which provides information on bone microarchitecture (21). A homogenous microarchitecture results in a higher TBS value, whereas a more heterogenous microarchitecture results in a lower TBS value. TBS can be easily measured from the lumbar spine DXA scans, which have been previously obtained to measure BMD (21). One of the major advantages of TBS is that it is not impacted by the presence of overlaying calcifications due to degenerative changes in the bone. In the general population, lower TBS values have been associated with higher fracture risk independently of BMD and/or other fracture clinical risk factors (22-25). It is now well-established that TBS is an independent predictor of fracture risk, suggesting its use in addition to BMD in fracture risk prediction (26). As a result, TBS is now incorporated into FRAX, the most widely used fracture risk assessment tool that uses a combination of age, sex, clinical risk factors and femoral neck BMD (optional) to predict the 10-years probability of major osteoporotic fracture (hip, humerus, forearm and clinical vertebral fractures) (27). Furthermore, studies have also demonstrated the ability of TBS to predict fragility fractures in secondary osteoporosis, caused by diabetes, primary hyperparathyroidism, rheumatoid arthritis, adrenal incidentaloma, chronic kidney disease, or long-term glucocorticoid therapy (28-31).

The aim of our study was to review the current scientific literature on TBS and chronic kidney disease. We identified studies that have investigated the ability of TBS to assess bone health and to predict fracture risk along the CKD spectrum or kidney transplantation.

\section{Literature Search}

Using both free text and MESH terms (trabecular bone score, chronic kidney disease, hemodialysis and kidney transplantation), a systematic search of the literature was performed in PubMed database with no time and study type limit, until January 2018. Abstracts were selected. References of the retrieved articles were checked manually for further studies.

\section{TBS in Patients With Reduced Kidney Function}

KDIGO defines the reduced kidney function as GFR $<60$ $\mathrm{ml} / \mathrm{min}$ per $1.73 \mathrm{~m}^{2}$ and normal kidney function as GFR $\geq 60$ $\mathrm{ml} / \mathrm{min}$ per $1.73 \mathrm{~m}^{2}$ (1). The reduced kidney function is further classified in stages $3 a-4$, as stated above. Naylor et al. studied the association of TBS with fracture risk in reduced kidney function and examined whether this association differs from that with normal kidney function, in the Canadian Multicenter Osteoporosis Study (32). Adults ( $>40$ years) with reduced kidney function $(n=199)$ had a significantly lower mean TBS than those with normal kidney function ( $n=1.227 ; 1.275$ vs. 1.297$)$. The 5 years probability of having a fragility fracture was higher among individuals with reduced kidney function with TBS values below the median (18.1\%; 95\% CI: 11.7-27.6\%) than those with TBS values above the median (6.2\%; 95\% CI: $2.8-13.3 \%)$. Moreover, TBS showed to predict fracture independently of age, sex, FRAX score, and BMD in both groups. These results suggest that as in the general population, TBS may be a useful parameter to predict fracture risk in patients with reduced kidney function.

\section{TBS in Patients on Hemodialysis}

Fractures occur more frequently in hemodialysis patients than in the general population (33). For instance, patients receiving 
hemodialysis therapy have a 4 -fold higher incidence of hip fracture than the general population. Furthermore, hip fracturerelated mortality risk is two times higher with a GFR $<45$ than GFR $\geq 45 \mathrm{ml} / \mathrm{min}$ per $1.73 \mathrm{~m}^{2}(11,34,35)$. Scientific evidence has very recently supported some fracture risk predictive value of BMD in patients with end-stage renal disease (ESRD) (CKD stage 4-5) and/or on dialysis (17-20). Nevertheless, there is a lack of investigation of other bone parameters measured from DXA, such as TBS in fracture risk prediction in ESRD patients. To the best of our knowledge, two studies have evaluated TBS in this group of patients.

Yavropoulou et al. studied the possible association of TBS with other factors that reflect bone health in a cross-sectional case-control study of 50 patients with ESRD undergoing chronic hemodialysis (36). Participants were 23 women and 27 men with a mean age of $62 \pm 9.6$ years. The control group were 52 healthy individuals (mean age $=59 \pm 9.5$ years) matched for age, body mass index and gender. Patients on hemodialysis had a significantly lower TBS than controls $(1.11 \pm 0.16$ vs. $1.30 \pm 0.13$, $p<0.001$, respectively) and this difference remained significant even after adjusting for age and serum levels of parathyroid hormone, phosphate, alkaline phosphatase, and 25-OH-vitamin D3. Furthermore, TBS was significantly lower among patients on dialysis without osteoporosis than controls without osteoporosis, and this was independent of BMD or other covariates (1.15 \pm 0.181 vs. $1.32 \pm 0.123, p=0.001$, respectively).

In the second study, Brunerova et al. aimed to contribute further to the study of the utility of TBS in the ESRD patients on dialysis (37). They assessed TBS in 59 patients (mean age $=67.6 \pm 13.1$ years) on dialysis concluding that half of them had severely impaired bone microarchitecture as assessed by TBS. They additionally saw that there was a good correlation between TBS and quantitative computed tomography (QCT), which reflected the histomorphometric parameters. Thus, TBS seems to be an effective and non-invasive indirect marker of bone microarchitecture. Their data were too limited to further investigate the utility of TBS in fracture risk prediction.

\section{TBS in Kidney Transplant Recipients}

Kidney transplantation has the best prognosis for patients with severe end-stage renal failure (38). Improving the long-term quality of life for these patients is an important matter. There are contradictory results from studies that have investigated the association of fracture risk with renal transplant. Risk factors, such as duration of prior renal failure or dialysis, diabetes, corticosteroids use have been associated, but not robustly, with the increase in fracture risk after renal transplantation. Nevertheless, the field lacks a well-established way to predict fracture risk in these patients. The majority of studies on TBS and CKD, actually are on the kidney transplant patients, as the most vulnerable/exposed category of CKD patients to bone damage.

Naylor et al. investigated TBS in 327 adults kidney transplant recipients (mean age $=45.3 \pm 12.4$ years) who received their transplant in Manitoba, Canada; and compared it with 981 matched healthy individuals (mean age $=45.4 \pm 12.3$ years) (39). Kidney transplant recipients had a significantly lower TBS compared to controls $(1.365 \pm 0.129$ vs. $1.406 \pm 0.125, p<0.001)$ and a higher fracture probability as assessed by FRAX. During the mean follow-up period of 6.6 years, 31 (9\%) kidney transplant recipients sustained one or more incident fragility fractures. The recipients who sustained a fracture had a significantly lower TBS than those who did not $(1.301 \pm 0.144$ vs. 1.372 $\pm 0.125, p=0.003)$. TBS was able to discriminate between recipients with and without a fracture (area under the curve 0.64; 95\%CI: $0.53-0.74, p=0.012$ ). Furthermore, the kidney transplant recipients with a lower TBS were less likely to remain fracture-free $(p=0.017)$. Finally, lower TBS was associated with fracture independent of FRAX (adjusted hazard ratio per standard deviation decrease 1.55; 95\%CI: 1.06-2.27).

Peres-Saez et al. performed a cross-sectional study to analyze bone health outcomes in 53 ESRD patients (mean age $=55.8$ \pm 12.1 years) at the time of undergoing kidney transplant surgery (40). The control group was 77 healthy individuals (mean age $=50.2 \pm 16$ years). TBS was measured in a mean time of 8 days after the kidney transplant surgery. TBS was higher in the control group than in cases (1.20, interquantiles range IQR: $1.11-1.3$ vs. 1.31 , IQR: $1.19-1.43, p<0.001)$. The duration of dialysis before the transplant showed to have no effect on TBS post-transplant.

Moreover, Perez-Saez et al. investigated TBS also in long-term (mean follow-up time $=10$ years) kidney transplant patients in the same population with the previous study (41). The 40 cases (mean age $=63.8 \pm 11.1$ years) were matched with 77 healthy controls (mean age $=50.2 \pm 16$ years). TBS was again lower among the cases than controls, but did not reach a statistical significance $(1.21 \pm 0.14$ vs. $1.30 \pm 0.15, p=0.072)$. Interestingly, no differences in TBS or BMD between patients on glucocorticoids and those glucocorticoids-free were found; neither a correlation between TBS or BMD with the cumulative glucocorticoid dose.

Luckman et al. followed 47 kidney transplant recipients (mean age $=50.5 \pm 13.7$ years) for 12 months after their kidney transplant (42). All patients underwent DXA scans at baseline, 3, 6, and 12 months after the transplant surgery. At baseline and at 12 -months visit, 72 and $76 \%$, respectively, of the patients had normal BMD-which was in contrast to TBS, as only 47 and $50 \%$, respectively, of the patients had TBS values that corresponded to a low fracture risk (TBS $\geq$ 1.37). Nevertheless, $42 \%$ of the patients having normal BMD values, were classified to the high fracture risk group by their TBS values. TBS correlated to the high-resolution peripheral quantitative computed-tomography (HR-pQCT) measures of trabecular bone: trabecular thickness, density, stiffness and failure load. Furthermore, despite having normal lumbar spine BMD values, patients classified as high risk by TBS had abnormal cortical and trabecular microarchitecture and lower bone strength as assessed from the computational measures. In general, older age and a history of pre-transplantation dialysis were associated with a lower TBS at baseline; whereas male sex, pre-transplant diabetes and elevated levels of bone resorption marker (carboxy-terminal collagen crosslinks) were risk factors for declines in TBS during the follow-up period.

Most recently, Aleksova et al. investigated TBS in 146 patients (mean age $=48 \pm 13$ years) with progressed CKD (stage 5 on dialysis) who had undergone a kidney ( $n=114$ patients) or simultaneous pancreas kidney transplantation ( $n=33$ patients) 
(43). The mean TBS value was $1.345 \pm 0.125$ and $\mathrm{TBS} \geq 1.31$, which indicates a lower risk of microarchitecture damage, was present in $65 \%$ of the study population, whereas $15 \%$ of them had a TBS $<1.23$ which indicates a high risk for microarchitecture damage. TBS did not significantly differ with sex, age or prior dialysis duration. Patients with type 1 diabetes undergoing simultaneous pancreas kidney transplantation had lower TBS values than those undergoing only kidney transplantation. Furthermore, prevalent non-vertebral fractures were significantly associated with lower TBS values $(p=0.023)$. Low TBS values $(\leq 1.31)$ were a good predictor of non-vertebral fractures, but not of combined vertebral and non-vertebral fractures. Even after adjusting for the relevant covariates, TBS remained significantly associated with prevalent non-vertebral fractures independently of femoral neck BMD and FRAX (odds ratio per standard deviation decline in TBS $=1.54 ; 95 \% \mathrm{CI}$ : $1.03-2.31 ; p=0.036$ ).

\section{DISCUSSION}

To the best of our knowledge, this is the first literature review of the utility of TBS in bone health assessment and fracture risk prediction in patients with chronic kidney disease undergoing dialysis or kidney transplantation. In general, these studies are in line with each other in associating lower TBS values with an impaired kidney function along the CKD spectrum and among the kidney transplant recipients; and concluding that TBS can predict fracture risk independently of bone density in this population.

The lack of a well-established strategy to assess bone health and fracture risk in patients with end-stage renal disease is an important matter of bone community. The presence of bone health deterioration in these patients could have possible therapeutic implications which could decrease the risk of having a fragility fracture and furthermore, improve their prognosis. The current gold standard method to assess bone deterioration, bone biopsy, is an invasive technique with a limited availability (3). Thus, research has been focused on the investigation of non-invasive measurements of bone strength that would predict fractures in this population. Recent studies concluded that the utility of BMD, one of the bone parameters used in the general population to predict fragility fractures and assess bone health, is valuable in the management of ESRD patients with MBD (17-20). As in the general population, BMD measurement alone cannot always estimate the severity of bone disease (14). Hence, the investigation of the utility of TBS, as another non-invasive bone parameter that have shown to be independent of $\mathrm{BMD}$, in this population, has gained special attention.

In patients with ESRD on hemodialysis, TBS suggests that a significant deterioration of bone quality might be present, independent of bone mass and other biochemical changes in ESRD, postulating itself as a valuable marker in assessing bone quality in these patients $(36,37)$. Nevertheless, the small sample sizes of the current studies on this topic, could not allow the full investigation of TBS predictive value in the risk of fragility fractures.
The majority of studies on TBS and CKD are on kidney transplant recipients, as an exposed group to ESRD and other causes of osteoporosis, such as glucocorticoids use. They have robustly shown that patients who had undergone a kidney transplant had a lower TBS than matched controls, suggesting of a remained bone microarchitecture alteration after the kidney transplant $(39,40,42,43)$. Potential mechanisms that might explain this bone loss include the damage caused from the pre-transplant ESRD; the exposure to agents, such as glucocorticoids after the transplant, which has its major effect on bone health, affecting its microarchitecture as well; and postoperative immobility followed by increased physical activity due to improved health status $(3,44-48)$. Nevertheless, the only study with a long-term follow-up period of the patients, 10 years after their kidney transplant surgery, demonstrated an almost complete recovery of bone quality as measured from TBS (41). Interestingly and contrary to what was expected, this study also showed no differences in bone assessments among patients who were on glucocorticoids and those who were not-suggesting that further investigation of the long-term effect of glucocorticoids on bone in this population is needed. Furthermore, TBS was shown to be a good fracture risk predictor in this patients' category.

The wide range of TBS values in patients with reduced kidney function (32), on hemodialysis $(36,37)$ and kidney transplant recipients (38-43) does not allow us to speculate on an association between the deterioration of renal function and decline in TBS. Nevertheless, the results of the studies reported in this review cannot be compared due to the differences in characteristics, such as age or body mass index, and the DXA devices used in the studied populations. The exploration of this relationship and the suggestive TBS thresholds to be used in clinical practice for this patients' category in larger followup case-control studies would help to further elaborate on this matter.

In overall, current evidence suggests that the management of bone health alterations and fracture risk assessment among patients with $\mathrm{CKD}$ and those after kidney transplantation, might be similar to that of the non-CKD population. The studies robustly show a damage of bone microarchitecture as measured by TBS (and consistent with findings from other technics, such as HR-pQCT), and confirm the ability of TBS to predict the risk of fragility fractures in this population. Based on these insights, TBS assessment is reasonable in the fracture risk prediction in this population. Additional investigation on the TBS thresholds in this population will eventually contribute to the improvement of their clinical management.

\section{AUTHOR CONTRIBUTIONS}

All authors listed have made a substantial, direct and intellectual contribution to the work, and approved it for publication.

\section{FUNDING}

This work was supported from the Swiss National Fund (32473B_156978) and the Foundation of the Orthopedic Hospital of the LUMC, Lausanne, Switzerland. 


\section{REFERENCES}

1. Ketteler M, Block GA, Evenepoel P, Fukagawa M, Herzog CA, McCann L, et al. Diagnosis, evaluation, prevention, and treatment of chronic kidney diseasemineral and bone disorder: synopsis of the kidney disease: improving global outcomes 2017 clinical practice guideline update. Ann Intern Med. (2018) 168:422-30. doi: 10.7326/M17-2640

2. Gordon PL, Frassetto LA. Management of osteoporosis in CKD Stages 3 to 5. Am J Kidney Dis. (2010) 55:941-56. doi: 10.1053/j.ajkd.2010.02.338

3. Kidney Disease: Improving Global Outcomes CKDMBDWG. KDIGO clinical practice guideline for the diagnosis, evaluation, prevention, and treatment of chronic kidney disease-mineral and bone disorder (CKD-MBD). Kidney Int Suppl. (2009) 113:S1-130. doi: 10.1038/ki.2009.188

4. Jamal SA, Miller PD. Secondary and tertiary hyperparathyroidism. J Clin Densitom. (2013) 16:64-8. doi: 10.1016/j.jocd.2012.11.012

5. Jamal SA, West SL, Miller PD. Bone and kidney disease: diagnostic and therapeutic implications. Curr Rheumatol Rep. (2012) 14:217-23. doi: 10.1007/s11926-012-0243-9

6. Miller PD. Unrecognized and unappreciated secondary causes of osteoporosis. Endocrinol Metab Clin North Am. (2012) 41:613-28. doi: 10.1016/j.ecl.2012.05.005

7. Juppner H, Wolf $M$, Salusky IB. FGF-23: more than a regulator of renal phosphate handling? J Bone Miner Res. (2010) 25:2091-7. doi: $10.1002 / \mathrm{jbmr} .170$

8. Cejka D, Herberth J, Branscum AJ, Fardo DW, Monier-Faugere MC, Diarra D, et al. Sclerostin and Dickkopf-1 in renal osteodystrophy. Clin J Am Soc Nephrol. (2011) 6:877-82. doi: 10.2215/CJN.06550810

9. Hamdy NA, Kanis JA, Beneton MN, Brown CB, Juttmann JR, Jordans JG, et al. Effect of alfacalcidol on natural course of renal bone disease in mild to moderate renal failure. BMJ (1995) 310:358-63. doi: 10.1136/bmj.310.6976.358

10. Coen G, Ballanti P, Bonucci E, Calabria S, Costantini S, Ferrannini M, et al. Renal osteodystrophy in predialysis and hemodialysis patients: comparison of histologic patterns and diagnostic predictivity of intact PTH. Nephron (2002) 91:103-11. doi: 10.1159/000057611

11. Alem AM, Sherrard DJ, Gillen DL, Weiss NS, Beresford SA, Heckbert $\mathrm{SR}$, et al. Increased risk of hip fracture among patients with end-stage renal disease. Kidney Int. (2000) 58:396-9. doi: 10.1046/j.1523-1755.2000.0 0178.x

12. Ball AM, Gillen DL, Sherrard D, Weiss NS, Emerson SS, Seliger SL, et al. Risk of hip fracture among dialysis and renal transplant recipients. JAMA (2002) 288:3014-8. doi: 10.1001/jama.288.23.3014

13. Nickolas TL, McMahon DJ, Shane E. Relationship between moderate to severe kidney disease and hip fracture in the United States. J Am Soc Nephrol. (2006) 17:3223-32. doi: 10.1681/ASN.2005111194

14. Pimentel A, Urena-Torres P, Zillikens MC, Bover J, Cohen-Solal M. Fractures in patients with CKD-diagnosis, treatment, and prevention: a review by members of the European Calcified Tissue Society and the European Renal Association of Nephrology Dialysis and Transplantation. Kidney Int. (2017) 92:1343-55. doi: 10.1016/j.kint.2017.07.021

15. Pocock N. Use of dual energy X-ray absorptiometry, the trabecular bone score and quantitative computed tomography in the evaluation of chronic kidney disease-mineral and bone disorders. Nephrology (Carlton) (2017) 22:19-21. doi: 10.1111/nep.13016

16. Miller PD. Chronic kidney disease and the skeleton. Bone Res. (2014) 2:14044. doi: 10.1038/boneres.2014.44

17. Iimori S, Mori Y, Akita W, Kuyama T, Takada S, Asai T, et al. Diagnostic usefulness of bone mineral density and biochemical markers of bone turnover in predicting fracture in CKD stage 5D patients-a single-center cohort study. Nephrol Dial Transplant. (2012) 27:345-51. doi: 10.1093/ndt/ gfr317

18. Naylor KL, Garg AX, Zou G, Langsetmo L, Leslie WD, Fraser LA, et al. Comparison of fracture risk prediction among individuals with reduced and normal kidney function. Clin J Am Soc Nephrol. (2015) 10:646-53. doi: 10.2215/CJN.06040614

19. West SL, Lok CE, Langsetmo L, Cheung AM, Szabo E, Pearce D, et al. Bone mineral density predicts fractures in chronic kidney disease. J Bone Miner Res. (2015) 30:913-9. doi: 10.1002/jbmr.2406
20. Yenchek RH, Ix JH, Shlipak MG, Bauer DC, Rianon NJ, Kritchevsky SB, et al. Bone mineral density and fracture risk in older individuals with CKD. Clin J Am Soc Nephrol. (2012) 7:1130-6. doi: 10.2215/CJN.12871211

21. Silva BC, Leslie WD, Resch H, Lamy O, Lesnyak O, Binkley N, et al. Trabecular bone score: a noninvasive analytical method based upon the DXA image. $J$ Bone Miner Res. (2014) 29:518-30. doi: 10.1002/jbmr.2176

22. Boutroy S, Hans D, Sornay-Rendu E, Vilayphiou N, Winzenrieth R, Chapurlat R. Trabecular bone score improves fracture risk prediction in non-osteoporotic women: the OFELY study. Osteoporos Int. (2013) 24:77-85. doi: $10.1007 / \mathrm{s} 00198-012-2188-2$

23. Rabier B, Heraud A, Grand-Lenoir C, Winzenrieth R, Hans D. A multicentre, retrospective case-control study assessing the role of trabecular bone score (TBS) in menopausal Caucasian women with low areal bone mineral density (BMDa): analysing the odds of vertebral fracture. Bone (2010) 46:176-81. doi: 10.1016/j.bone.2009.06.032

24. Hans D, Goertzen AL, Krieg MA, Leslie WD. Bone microarchitecture assessed by TBS predicts osteoporotic fractures independent of bone density: the Manitoba study. J Bone Miner Res. (2011) 26:2762-9. doi: 10.1002/jbmr.499

25. Popp AW, Meer S, Krieg MA, Perrelet R, Hans D, Lippuner K. Bone mineral density (BMD) and vertebral trabecular bone score (TBS) for the identification of elderly women at high risk for fracture: the SEMOF cohort study. Eur Spine J. (2016) 25:3432-8. doi: 10.1007/s00586-015-4035-6

26. McCloskey EV, Oden A, Harvey NC, Leslie WD, Hans D, Johansson $\mathrm{H}$, et al. A meta-analysis of trabecular bone score in fracture risk prediction and its relationship to FRAX. J Bone Miner Res. (2016) 31:940-8. doi: $10.1002 / j b m r .2734$

27. Kanis JA, Harvey NC, Johansson H, Oden A, Leslie WD, McCloskey EV. FRAX update. J Clin Densitom. (2017) 20:360-7. doi: 10.1016/j.jocd.2017.06.022

28. Leslie WD, Aubry-Rozier B, Lamy O, Hans D, Manitoba Bone Density P. TBS (trabecular bone score) and diabetes-related fracture risk. J Clin Endocrinol Metab. (2013) 98:602-9. doi: 10.1210/jc.2012-3118

29. Breban S, Briot K, Kolta S, Paternotte S, Ghazi M, Fechtenbaum J, et al. Identification of rheumatoid arthritis patients with vertebral fractures using bone mineral density and trabecular bone score. J Clin Densitom. (2012) 15:260-6. doi: 10.1016/j.jocd.2012.01.007

30. Ulivieri FM, Silva BC, Sardanelli F, Hans D, Bilezikian JP, Caudarella R. Utility of the trabecular bone score (TBS) in secondary osteoporosis. Endocrine (2014) 47:435-48. doi: 10.1007/s12020-014-0280-4

31. Paggiosi MA, Peel NF, Eastell R. The impact of glucocorticoid therapy on trabecular bone score in older women. Osteoporos Int. (2015) 26:1773-80. doi: 10.1007/s00198-015-3078-1

32. Naylor KL, Prior J, Garg AX, Berger C, Langsetmo L, Adachi JD, et al Trabecular bone score and incident fragility fracture risk in adults with reduced kidney function. Clin J Am Soc Nephrol. (2016) 11:2032-40. doi: 10.2215/CJN.00720116

33. Aggarwal HK, Jain D, Yadav S, Kaverappa V. Bone mineral density in patients with predialysis chronic kidney disease. Ren Fail. (2013) 35:1105-11. doi: 10.3109/0886022X.2013.815102

34. Maravic M, Ostertag A, Urena P, Cohen-Solal M. Dementia is a major risk factor for hip fractures in patients with chronic kidney disease. Osteoporos Int. (2016) 27:1665-9. doi: 10.1007/s00198-015-3429-y

35. Nitsch D, Mylne A, Roderick PJ, Smeeth L, Hubbard R, Fletcher A. Chronic kidney disease and hip fracture-related mortality in older people in the UK. Nephrol Dial Transplant. (2009) 24:1539-44. doi: 10.1093/ndt/gfn678

36. Yavropoulou MP, Vaios V, Pikilidou M, Chryssogonidis I, Sachinidou M, Tournis S, et al. Bone quality assessment as measured by trabecular bone score in patients with end-stage renal disease on dialysis. J Clin Densitom. (2017) 20:490-7. doi: 10.1016/j.jocd.2016.11.002

37. Brunerova L, Ronova P, Veresova J, Beranova P, Potoekova J, Kasalicky P, et al. Osteoporosis and impaired trabecular bone score in hemodialysis patients. Kidney Blood Press Res. (2016) 41:345-54. doi: 10.1159/000443439

38. Pascual M, Theruvath T, Kawai T, Tolkoff-Rubin N, Cosimi AB. Strategies to improve long-term outcomes after renal transplantation. N Engl J Med. (2002) 346:580-90. doi: 10.1056/NEJMra011295

39. Naylor KL, Lix LM, Hans D, Garg AX, Rush DN, Hodsman AB, et al. Trabecular bone score in kidney transplant recipients. Osteoporos Int. (2016) 27:1115-21. doi: 10.1007/s00198-015-3424-3 
40. Perez-Saez MJ, Herrera S, Prieto-Alhambra D, Vilaplana L, Nogues X, Vera M, et al. Bone density, microarchitecture, and material strength in chronic kidney disease patients at the time of kidney transplantation. Osteoporos Int. (2017) 28:2723-7. doi: 10.1007/s00198-017-4065-5

41. Perez-Saez MJ, Herrera S, Prieto-Alhambra D, Nogues X, Vera M, Redondo-Pachon D, et al. Bone density, microarchitecture, and tissue quality long-term after kidney transplant. Transplantation (2017) 101:1290-4. doi: 10.1097/TP.00000000000 01328

42. Luckman M, Hans D, Cortez N, Nishiyama KK, Agarawal S, Zhang $\mathrm{C}$, et al. Spine trabecular bone score as an indicator of bone microarchitecture at the peripheral skeleton in kidney transplant recipients. Clin J Am Soc Nephrol. (2017) 12:644-52. doi: 10.2215/CJN.098 50916

43. Aleksova J, Kurniawan S, Elder GJ. The trabecular bone score is associated with bone mineral density, markers of bone turnover and prevalent fracture in patients with end stage kidney disease. Osteoporos Int. (2018) 29:1447-55. doi: 10.1007/s00198-018-4468-y

44. Pichette V, Bonnardeaux A, Prudhomme L, Gagne M, Cardinal J, Ouimet D. Long-term bone loss in kidney transplant recipients: a crosssectional and longitudinal study. Am J Kidney Dis. (1996) 28:105-14. doi: 10.1016/S0272-6386(96)90138-9

45. Weisinger JR, Carlini RG, Rojas E, Bellorin-Font E. Bone disease after renal transplantation. Transplant Proc. (1999) 31:3033-4. doi: 10.1016/S0041-1345(99)00658-2
46. Canalis E. Clinical review 83: mechanisms of glucocorticoid action in bone: implications to glucocorticoid-induced osteoporosis. J Clin Endocrinol Metab. (1996) 81:3441-7.

47. Manolagas SC, Weinstein RS. New developments in the pathogenesis and treatment of steroid-induced osteoporosis. J Bone Miner Res. (1999) 14:10616. doi: 10.1359/jbmr.1999.14.7.1061

48. Chevalley T, Strong DD, Mohan S, Baylink D, Linkhart TA. Evidence for a role for insulin-like growth factor binding proteins in glucocorticoid inhibition of normal human osteoblast-like cell proliferation. Eur J Endocrinol. (1996) 134:591-601. doi: 10.1530/eje.0.1340591

Conflict of Interest Statement: DH is co-owner of the TBS patient and has corresponding ownership and position at medimaps group.

The remaining authors declare that the research was conducted in the absence of any commercial or financial relationships that could be construed as a potential conflict of interest.

Copyright (c) 2018 Shevroja, Lamy and Hans. This is an open-access article distributed under the terms of the Creative Commons Attribution License (CC BY). The use, distribution or reproduction in other forums is permitted, provided the original author(s) and the copyright owner(s) are credited and that the original publication in this journal is cited, in accordance with accepted academic practice. No use, distribution or reproduction is permitted which does not comply with these terms. 